earth's surface the atmospheric rarefaction must be such as to convert what would be lightning at a lower leve into a discharge similar in the main to that in a vacuum tube.

Furtber, it is an ascertained fact that a difference of electrical condition in different portions of the atmosphere often prevails. We have, therefore, not unfrequently present in regious at moderate elevations, say from twenty to fifty miles, all the conditions necessary for the production of an auroral display.

And $n$ )t only so, but our experiments enable us to determine, at all events approximately, some limits of elevation within which this phenomenon can occur, and thereby to check the very divergent esti nates of those who have observed it. Estimates of the altitude at which the auroral discharge takes place have been mide from simultaneous observations at different points, and these have ranged up to fifty or sixty, and eve $x$ to $28 \mathrm{I}$ miles. But even the lowest of these appears to be improbable. The pressure at which the resistance of air is least is a little less than 4 of a millimetre of mercury; and the corresponding elevation is about thirty-eight miles. A vacuum tuhe meacured by hundred-thousandths of an atmosphere would correspond to an elevation of a little more than eighty-one miles. Through a hydroge ? vacuum at this pressure Mr. De La Rue failed to obtain a discharge with II, 0oo cells; : nd he add : that "it may be assumed that at this height the discharge would be considerably less brilliant than at thirty-eight miles, should such occur."

It seems to be a well-ascertained fact that in high latitude there are fewer thunderstorms and more auroras than in lower latitudes. This fact points to the conclusion that, after a dis'urb ance, the re-distribution of atmospheric electricity is effected by one process or by the other, according to, or rather in consequence of, the meteorological differences between arctic, temperate, and tropical regions. In colder regions, where the air is generally drier, and, consequently, a better insulato: than in warmer, there is less liability to a discharge taking place in the lower and denser strata; that is, there is less liability to lightning. But at higher levels the rarefaction may compensate this, and cause an auro al discharge t.) take place inistead.

There are other features in which a comparison may be made between the auroral light and vacuum discharge. These discharge; when free to arrange themselves in a magnetic field, follow the lines of force; the auroral streamers appear to run parallel to the dipping needle. The colour of such discharges varies with the exhaustion; that of the aurora varies, like that of an air-vacuum, from red almost to white; and in the absence of independent observations to the contrary, we may fairly attribute the variety of tint in the aurora partly to a diversity of elevation, and, consequently, of rarefaction in the region where it takes place, but partly also perbaps to the electrical conditions present anterior to the passage of the di:charse.

These and other features of the phenomenon of the aurora, as well as the kindred subjects of earth currents, the disturbances of the magnetic needle, and the connection of the whole with solar radiation as a predisposing cause, have been brought together under one theoretic view by Prof. Stokes, to whom I am indebted for much of what I have here said on the subject.

Having thus gone throngh, so far as circumstanc s permitted, the experimental and inductive parts of my subject, it might have been very pleasant to have cast aside for a few moment the links which connect strict induction with what may be termed the fixed points of ascertained fact ; and, restrained only by the more elastic bonds of scientific imagination, to have indulged in speculations about things still lying on the borders of science and of dreamland. But I must leave each of you to follow out this vein of thourht after your own fashion; and, confinin myself to a single remark, I will simply indicate the direction in which my own thoughts on the present subject are inclined to turn. The remark is this: If in the search for a solution of the mystery of electricity there be one element more deserving our attention rather than another, it is that of time. We have utilised this element in our experiments with the revolving mirror; and we have touched upon its more subtle influences in our conclusions about the small time quantities in relation to the discharge.

All operations of nature take place in time. It is in the timesequence of phases, often apparently simultaneous, but in reality successive, that we may hope to strike the origin of many complicated phenomena. Time is the ocean beneath whose waves and whose currents the secret fountains of truth are to be sought. Time is the ocean whose mighty stream encircles our life. Time is the ocean whose "countless smiles" gave birth to Venus and the Nereids and all the infinite forms of beauty and of brightness which play around our youth. Time is the ocean from whence sprang also the steeds of Neptune, typical of the strength of our mo e mature years. Time is the ocean in whose loving arms we fall asleep, when the sun sinks low on the horizon, and the shades of night are creeping over the heavens, and all things tell us that our course is run.

\section{BIOLOGY AS AN ACADEMICAL STUDY} II.

I T may help to the understanding of what I mean by a sound method of biological teaching if I give a brief outline of the course of study I hope to pursue with my students this session. It is hardly necessary for me to state that this course is derived from Prof. Huxley's by a natural process of descent with modification.

In the first place there will be some four or five lecture; on a common flowering plant, giving an account of its ordinary structure as seen by the naked eye, of its microscopic structure, of its physiol igy, and of the process of its development. After each lecture the students will examine for themselves the plant described, learning not only to dissect it in the ordinary way, but to make preparations for the microscope. By this means they will be familiarised with the use of the microscope, the employment of stainin $y$ fluids, and other reagents used in the investigation of minute structure, and with the chief processes of manipulation. As the laboratory will be ojen for nine hours a week, so $a ;$ to give three hours for working out what has been described in each hour's lecture, it is to be expected that a student of average intelligence will, by the time this part of the course is over, have a very fair notion of what a flowering plant is, of the procesies by which its life is carried on, and of the manner in which it originates.

The next few lectures, and the corresponding portion of the practical course, will be occupied with a sinilar treatment of an animal: the one selected, as on the whole the most convenient and the most instructive, being the common sea crayfish of our markets. In the examination of this organism, the students will learn something of the art of dissection, and will further apply the knowledge of microscopic structure which the study of the plant has given them, to the far more difficult problems of animal histology. The study of the crayfish, and the comparison of it, point by point, with the plant, should give a clear conception of the main points of difference and of likeness between the more highly organised animals and plants--between aninials and plants as they are generally known to us.

In dealing with these types in the lectures it will be my aim always to proceed from the known to the unknown; to begin with points which every one who has seen a flowering plant or a crayfish mu-t have noticed, gradually leading up to such points of structure as require minute observation to verify them, and above all never to give a definition or a general statement without first supplying the facts from which it is legitimately deducible.

Next, I propose to take a number of types selected on the one hand from the lowest plants, on the other from the lowest animals: to show how these unicellular organisms agree in structure and in the nature of their physiological processes with the individual cells of which the bodies of the higher plants and animals are made up, and to point out how, in denlins with these lowest members of the two kingdoms of organic nature, the boundary line between the two kingdoms tends to disappear, and it becomes very difficu't, sometimes even impossible, to say what is a plant and what an animal. The study of these lowly forms will also lead to the question of the origin of life, and it will be necessary to say something of the attempts which have been made to establish the doctrine of spontaneous generation, and to discuis their value.

The consideration of a few other animal and vegetable types, especially such as, although multicellular, exhibit none of the complex tissues found in the higher animals and plants, will bring the introductory part of the course to a close-the part which deals with the general facts and principles of biology. In it the student should learn how animals and plants agree with and differ from each other, and from inorganic bodies; what are the relations of animals and plants to one another, and to

${ }^{x}$ Inaugural Lecture delivered in the University Library, May 2, $188 \mathrm{x}$, by T. Jeffery Parker, B.Sc., Lond., Professor of Biology in the University of Otago. Continued from p. 546. 
inorganic nature ; what is meant by differentiation of structure, and by the division of physiological labour exhibited by the higher organisms in contradistinction to the lower. He will also have gained some conception of the all-important truth that the higher organisms begin life as a simple cell, comparable to an entire unicellular organism, and that, of that cell, the animal or plant itself, as well as every element of its fully-formed tissues, is a lineal descendant. And these matters will be impressed upon his mind by actual verification of all the more important points; so that he will, it is hoped, have begun to learn the first duty of the student of science-to take things on trust only so long as be is unable to bring them to the test of observation and experiment.

The whole of this part of the course is a modification, adapted to I ical requirements, of Prof. Huxley's well-known "Genera Biology" course. It will be seen at once that it serves as an introduction both to botany and zoology, forming a startingpoint from which lectures on both these subjects may diverge. I hope to give a few lectures on structural botany on Monday evenings, but the remainder of the ordinary biology course will be purely zoological, dealing chiefly with animal morphology, or comparative anatomy, as opposed to systematic zoology. It is gradually being acknowleged by those most competent to form an opinion, that zoology in this latter sense is a subject of no educational value whatever-I mean as far as the beginner is concerned-since it necessarily follows a course exactly the opposite of that which the scientific novice should pursue. It begins with generalisations, and ends with details; it provides elaborate systems of classification without giving even an elementary knowledge of the totality of organisation of a single animal, and-what is most mischievous for the beginner-it regularly ignores facts not of "classificatory importance," and so tends to offer a premium on superficiality.

The principal groups of animals will therefore be treated partly by the description of "types," selected as exhibiting the chief characteristics of the group, partly by the comparative method-that is, by taking up a particular organ or set of organs and tracing the modifications it presents through a series of groups. The more important fossil members of any division will be considered along with the recent forms, a good deal will be said of the embryology or development of the chief types, and the main facts of their distribution in space and time will be considered, as well as the question of classification and the principles upon which it is conducted.

From time to time the necessity will arise of discussing the relations between these several divisions of the subject and the explanations of them. It will be shown, for instance, that a proximate explanation of the extraordinary changes undergone by an animal in its development from the egg is afforded by the theory that the evolution of the individual is a recapitulationmuch abbreviated and distorted-of the evolution of the species. Or, to take another example, it will be pointed out that in the doctrine of evolution we have the only satisfactory explanation of the fact that in tracing back the history in past time of many groups, the boundaries between them tend to disappear, and species are found at last assignable to no existing group, but combining in themselves the character of two or more. As a striking example I may mention the recent discovery of the second known specimen of the fossil called Archaopteryx, hitherto supposed to be a true bird, although exhibiting certain approximations towards reptiles. It is now known that Archæopteryx is completely intermediate between reptiles and birds-that it is indeed a feathered reptile; and it cannot be doubted that we have here clearly indicated the line of descent of the group of birds, at the present day so sharply separated from all other vertebrate animals. In the same way the mammalia, when traced back to the earlier tertiaries, are found to be represented by animals which are neither marsupials nor rodents, carnivores nor herbivores, but form a common group of generalised forms, from which the well-marked orders of mammals as we know them to-day are seen gradually to diverge as we trace the fossils from the lower to the upper tertiaries.

While this the greater part of the course is going on, the laboratory work will consist in the dissection of one or more common animals selected as types of each of the chief groups. The Molluca, for instance, will be illustrated by the cockle or mussel, the slug, and perhaps the octopus; the great group of articulated animals by the crab, sandhopper, beetle, moth, spider, millepede, \&c. ; the Vertebrata by some common fish, such as the red cod, by a frog if it can be had, by a pigeon and a rabbit. In thi; way the student will become familiar with the entire organisation of a sufficient number of animal types to enable him to understand the description of other types given him in lectures or in books. Further illustrations of many points of importance will be afforded him by the examination of specimens from the museum, notably in the case of fossils, and in that of the skele. ton, which latter, apart from its purely scientific importance, affords an excellent training for the faculties of observation, of comparison, and of memory. Moreover, if the time holds out I hope to be able to let the students see for themselves some of the chief stages in the development of the common fowl-the most convenient starting-point for the study of embryology.

Lastly, from time to time short practical examinations will be held. Subjects will be provided differing from those already seen, and the student will be encouraged to investigate their structure without help, and to compare the results thus obtained with those of the more formal work.

I think no one will doubt that a course of this sort must furnish a true discipline. Whether as a discipline it is superior, cateris paribus, to a classical course-to a study of the grammar and construction of the Latin and Greek languages, and a certain acquaintance with their literature, I must leave to the decision of those who know more of the latter suhjects than myself. Certainly a consideration of the faculties the two studies are likely to bring into play, train, and develop, leads one, in the absence of other data, save the sad memories of one's own school work, to assign a distinctly higher value to scientific than to grammatical study as a mental training. But this point has been so often insisted on by men whose words carry weight that no remarks of mine are needed. What I consider it my busi ness to point out is the way in which a course in my own branch of natural science should, and the way in which it should not, be carried on, and I feel convinced that even those who have no knowledge of the subject will see that the training afforded by the course of which I have given a brief outline in observation, in induction and deduction, in the comparative method, and in the true understanding of the relations between cause and effect, is not easily surpassed, to say nothing of the less important, though by no means to be despised, training of the memory, and of the exercise of the imagination provided by theories of molecular structure, and their application to morphological and physiological problems.

As to the effect of these studies upon still higher faculties, I feel that I cannot do better than quote a well-known passage from a lecture of Prof. Huxley's, delivered nearly twenty-seven years ago. He says :- " There is yet another way in which natural history may, I am convinced, take a profound hold upon practical life, and that is by its influence on the finer feelings as the greatest of all sources of that pleasure which is derivable from beauty. I do not pretend that natural history knowledge, as such, can increase our sense of the beautiful in natural objects. I do not suppose that the dead soul of Peter Bell, of whom the great poet of Nature says-

$$
\begin{gathered}
\text { "A primrose by the river's brim } \\
\text { A yellow primrose was to him, } \\
\text { And it was nothing more,'- }
\end{gathered}
$$

would have been a whit removed from its apathy by the information that the primrose is a dicotyledonous exogen, with a monopetalous corolla and central placentation. But I advocate natural history knowledge from this point of view because it would lead us to seek the beauties of natural objects instead of trusting to chance to force them on our attention."

Indeed the elevating effect of science from this point of view is of quite the same nature as that of art, and with the alteration of a word or two the sentence put by Browning into the mouth of Fra Lippo Lippi expresses exactly the same idea as the passage I have just quoted :-

$$
\text { " For don't you mark?-We're made so that we love, }
$$

First when we see them painted, things we have passed

Perhaps a hundred tirres, nor cared to see;

And so they are better painted-better to

Which is the same thing. Art was given for that."

One may even go a step further and say, with the Laureate, that he who could know all about one single little flower would know "what God and man is."

I would draw attention to the fact that $I$ have said nothing as to what is often called the practical bearing of scientific instruc tion. Ald this purposely; for we who have the charge of higher education in the ordinary sense-as distinguished from professional or technical education-have nothing whatever to do with so-called practical ends. Our business is, as far as in us lies, to train the minds of our students-to teach them to think and to learn for themselves, knowing that whatever career they 
may choose, this sort of training will be of primary importance to them-will form indeed the surest foundation for any course of professional training they may afterwards choose to follow.

So far I have been considering only the elementary teaching of biology, devoting special attention to the course $I$ propose to adopt for preparing beginners for the Pass Degree, and with certain additions to the work, for Senior Scholarships. It still remains to say something about the course of study for Honours in the biological sciences.

It is enacted in the regulations of the New Zealand University by what seems to me one of the wisest rules in the calendar, ${ }^{2}$ that a candidate for honours in biology mu:t specialise-that is, must choose some special branch of either zoology or totany, and work up that branch as fully as his time and opportunity will allow. He has already, in taking his B.A. degree, proved his general acquaintance with zoology or bctany; he now has to show that, of some limited department of one of these sciences, he possesses more than a mere text-book knowledge.

Suppose, for instance, that a student selects the group of fishes as his special subject. It will be my duty to direct him to the more important works,$n$ ichthyology in the University and Museum libraries, so that while taling the most recent work on the general subject as his text-book, he may, when desirable, refer to the original sources of information and acquire the habit - most essential for a student of science- of seizing upon the points of real impoitance in a monograph or brochure. While undergoing this course of reading the candidate will dissect as many as possible of the more important New Zealand fishes, making careful notes and drawings of their anatomy, and comparing his results with the statements he finds in books.

But it is further enacted that the candidate for Honours shall send in the results of some original research. In the hypothetical case I have chosen the subject for investigation would most probably be an inquiry into some branch of fish anatomy as far as it could be worked out on New Zealand species-the nervous system, for instance, or the skull, or the digestive organs in one of the groups, or the detailed anatomy of some single species.

It is, I think, from this part of the Honours work that the conscientious student will derive the greatest benefit, and it is in the fostering of research on the part of its members that a university performs its highest duty. Until it assumes that position indeed, it is orly a step above the high school, differing from it in degree only, and not in kind. It is only when original work is directly encouraged, and indeed looked upon as the goal of university life rather than the taking of a degree or the gaining of a scholarship-in other words it is only when knowledge is not only communicated, but advanced, that a university takes its true place, not as a mere finishing school, but as a centre of sound learning.

In the case of the advanced student I repeat it is only when his work becomes in some slight degree original that he derives the greatest possible benefit from it. "Every man," says Carlyle, "is not only a learner but a doer : he learns with the mind given him what has been; but with the same mind he discovers further; he invents and devises somewhat of his own. Absolutely without originality there is no man." It is impossible to estimate the benefit to a man's whole nature of setting him to puzzle out something that has never been thoroughly worked out before, of putting him upon his mettle to spare no effort in the elucidation of the problem before him, and to "hold it crime to let a truth slip." If a man has anything in him this assuredly will bring it out, more than years of absorbing other men's thoughts and verifying other men's results. The problem he has set himself may seem to others quite insignificant, and its solution a matter of no moment-" "the pitifullest infinitesimal fraction of a product"-but to him it is all-important-."an ill-favoured thing, sir, but mine own."

This brings me to the last point I have to touch upon. It is to be hoped that a certain proportion of the students who study biology here may be brought to look upon it not as a means of education only, but as a pursuit to be carried on after leaving the University. It is interesting to notice how much scientific work in England has been and is done by what may be called

I I am sorry to see that the Senate at its recent meeting has adopted a regulation which cannot fail to lower immeasurably the standard of the Honours examination in biology. It is proposed in fact to make the candidate take up a special subject in both botany and zoology. A student, for instance, whose predilections are zoological, and who may never have studied botany at all, is to make a special study of "some one family of the vegetable kingdom," as well as of some group of animals. The inevitable result will be that one or both subjects will be crammed, and Honours will cease to have their legitimate value, and will become nothing more than a step beyond the Pass Degree. scientific amateurs, men who, while engaged in professional or business pursuits, devote their spare time to the advancement of some branch of natural knowledge. And I think I am justified in saying that New Zealand has hitherto been pre-eminent among the Colonies for following out in this respect the traditions of the Mother Country. To say nothing of botany, many grours of animals have already been thoroughly well worked up, ard considerable headway has been made with others; but "there remaineth yet very much land to be possessed," and one may venture to hope that workers from this University will before long begin to swell the Transactions of the New Zealand Institute and the publications of the Geological Survey. Upon any who may have this laudable ambition before them I would ven. ture to urge the advisability-I might almost say necessity - of acquiring a sound ard exact, although necessarily elementary knowledge of biology as a whole, before beginning to study any special branch. The work of a man who knows his own limited branch of science, and nothing beyond, is quite sure to be im. perfect, and will most probably be evanescent. The highe:t results are only to be obtained by studying a group or a species, not only in and for itself, but in connection with other groups or species, by keeping always in mind the possible connection of one's own results with those of others, by remembering that the objects one is studying are not isolated things like coins or postage-stamps, but are organisms, whose special characters have been impressed upon them by forces which have been at work from the beginning of all things.

Finally, it is just possible that some day one of our students may be brought to take up biology as a career. I need hardly say that such a one, besides completing his studies elsewhere, would be probably compelled, unless possessed of private means, to exercise his profession either in Europe or in America, since there is very little chance at present of more than one biological appointment in a decade falling vacant in this Colony. But a man with a love for his subject and not afraid of hard work, who, after learning all he could learn here, availed himself of the best teaching at' home-at London, Cambridge, or Heidelberg-would, I feel convinced, have every chance of success. $\mathrm{He}$ would never get rich; the present practical applications of biology are not such as insure fortunes. He would have all his life to be satisfied with an "aurea mediocritas" in matters of finance, but he could count upon what is even better than a large income-increasing joy and constant development through a thoroughly congenial life-work.

\section{UNIVERSITY AND EDUCATIONAL}

\section{INTELLIGENCE}

OXFORR. - The Colleges meet on Saturday, October I5, and the professorial lectures begin the following week. The professors and lecturers in physics have drawn up the following scheme of lectures and classes for the Michaelmas term :-Prof. Clifton lectures on Wednesday and Saturday on terrestrial magnetism, and Prof. Bartholomew Price lectures on Tuesday, Thursday, and Saturday on the dynamics of material systems. Mr. Hayes lectures on electrostatics (treated mathematically). Instruction in practical physics is given daily in the Clarendon Laboratory, under the direction of Prof. Clifton, Mr. Stocker, and Mr. Heaton. Mr. Stocker gives an experimental lecture on elementary mechanics, and $\mathrm{Mr}$. Heaton has a class for problems in elementary mechanics and physics. The above lectures are given in the University Museum. At Queen's College Mr. Elliot gives a course on geometrical and physical objects; at Christ Church Mr. Baynes gives a course on elementary heat and light ; and at Balliol Mr. Dixon gives a course on elementary magnetism and electricity.

On Tuesday the Fellows of Wadham College elected Mr. G. E. Thorley to the wardenship of the College, in place of Dr. Griffiths, resigned. It is understood that Dr. Griffiths will continue to reside at Oxford, and will remain a delegate of the University Press and of the Iocal Examinations.

An examination for Natural Science Scholarships begins on Thursday, October I3, at Exeter and Trinity Colleges. The scholar elected at Exeter will be expected to read for honours in the biological school, and the scholar elected at Trinity will be expected to read for honours in chemistry or physics.

An election to a Brackenbury Natural Science Scholarship at Balliol College will be held in November. Papers will be set in physics, chemistry, and biology. Candidates may offer themselves in two of these subject;, and may also take mathematics or an English essay. 